\title{
Risks Induced by Room Mining Goaf and Their Assessment: A Case Study in the Shenfu-Dongsheng Mining Area
}

\author{
Hengjie Luan ${ }^{1,2}\left(\mathbb{0}\right.$, , Huili Lin ${ }^{3}$, Yujing Jiang ${ }^{1,2,4, *(\mathbb{D})}$, Yahua Wang ${ }^{1,2}$, Jiankang Liu ${ }^{1,2}$ and \\ Pu Wang 1,2,* \\ 1 College of Mining and Safety Engineering, Shandong University of Science and Technology, Qingdao 266590, \\ China; luanjie0330@126.com (H.L.); 15054259665@163.com (Y.W.); sdustjk1@163.com (J.L.) \\ 2 State Key Laboratory of Mining Disaster Prevention and Control Co-founded by Shandong Province and the \\ Ministry of Science and Technology, Shandong University of Science and Technology, Qingdao 266590, China \\ 3 China Coal Research Institute, Beijing 100013, China; linhuili_1983@163.com \\ 4 Graduate School of Engineering, Nagasaki University, Nagasaki 852-8521, Japan \\ * Correspondence: jiang@nagasaki-u.ac.jp (Y.J.); 15854848872@163.com (P.W.); Tel.: +86-532-8605-8052 (Y.J.)
}

Received: 25 January 2018; Accepted: 26 February 2018; Published: 28 February 2018

\begin{abstract}
A large area of room mining goaf has been left throughout the history of coal mining worldwide. However, because the pillars cannot perpetually retain stability, the sudden collapse of a large area of goaf can occur. The existing large areas of room mining goaf have become a potential source of geological risks in mining areas with room mining goafs worldwide. To elucidate the distribution and state of the goafs, a survey of the characteristics of goafs was carried out by geophysical exploration and drilling methods. From this complete survey of room mining goafs, this paper has outlined eight common goaf risks, emphasizing the types of goaf risks that require precautions, and the formation mechanisms of each goaf risk has been analyzed. Considering that the occurrence of a risk may lead to several other risks and there is a certain interaction between the risks, more specific room mining goaf risk forms, causes and scopes of influence have been listed. It is advantageous to use a support vector machine, which is useful for small-sample problems, to assess the goafs. A support vector machine assessment model of room mining goafs was established, and sample training and verification were carried out. Comparing the risk assessment results with those of the field investigation, it can be seen that the evaluation model has a high accuracy. This work can greatly contribute to the prediction and prevention of risks induced by room mining goaf.
\end{abstract}

Keywords: room mining goaf; characteristics survey; risk type; risk assessment; support vector machine; goaf management

\section{Introduction}

The room mining method has been used throughout a considerable period of the history of coal mining worldwide [1]. It is widely used in many coal-producing countries, including the U.S., Australia, South Africa, India, and China [2-4]. Hence, a large area of room mining goaf has been left behind. In the room mining method, the goaf depends on the support of the coal pillars that are left behind in the goaf to maintain stability $[5,6]$. However, with time, the effect of natural weathering, creep, rupture, etc. will result in pillar size reduction and pillar strength degradation $[7,8]$. Pillar failure will eventually occur. Furthermore, the failure of a single pillar in the goaf can cause load transfer to the neighboring pillars [9]. An increase in the range of the coal pillar failure can lead to catastrophe throughout the whole goaf system. The collapse of a large area of the goaf will threaten the safety of underground workers, mining equipment and facilities and can even cause mine earthquakes $[10,11]$. 
Moreover, this type of collapse can cause risks to the environment, such as land waste, greenhouse and toxic gases, the degradation of soil quality and plant community structure, water resources waste. The risks have severely influenced the lives of local residents and the sustainability of the ecological environment [12,13]. For example, an extensive accident in a coal mine in South Africa caused four hundred and thirty-seven casualties in 1960 because of the "domino effect" [14] caused by the pillar failure, resulting in the collapse of approximately 900 pillars [15]. Moreover, many documents and reports have introduced and discussed the subsidence and destruction of the ground surface of the goaf [16]. According to the research on the surface deformation of the Pittsburgh mining area, American experts noted that the surface subsidence of the room mining goaf will not occur until a few years after mining. Within this area, more than $50 \%$ of the surface began to deform after 50 years or more. In June of 1986, a roof collapse accident, with an area of approximately $800 \mathrm{~m}^{2}$, occurred in the Beicun Coal Mine of the Datong mining area in China. This accident led to the roof collapse of the Beicun, Xiaonantou and Jiucaigou Coal Mines across an area of approximately $89,425 \mathrm{~m}^{2}$. The roof collapse accident was caused by the massive mining of coal pillars and resulted in 40 days of shutdown at four mines and an economic loss of over 208 million yuan. In areas such as the Henan Duli Iron Mine and Datong Yanya Coal Mine, the goaf formed by the room mining method several years ago, or even several tens of years ago, was not dealt with at that time, because it was stable. Later, the surface of the mining area collapsed across large areas due to the failure of some of the coal pillars and the occurrence of a chain reaction. Ultimately, the event had very serious consequences. In addition, the room mining goaf can also cause water inrush, coal spontaneous combustion and some other risks. In recent years, coal mining in Western China has increased greatly at a large scale, and mining disturbance has become more severe. Therefore, the risks induced by room mining goaf are more prominent. According to statistics, in the Yulin area in northern Shaanxi Province, China, 121 mine earthquakes with magnitudes greater than 2.0 occurred from 2004 to 2015 [17]. It can be seen that the existing large area of room mining goaf has become a potential source of geological risks in these mining areas. It is necessary to evaluate and control the risk induced by the existing goaf. To evaluate the long-term stability of room mining goafs, Yang Yu [2] proposed a pillar peeling model and found that the damage level of the pillar peeling is affected by the peel angle and pillar height. Ebrahim Ghasemi [18] developed predictive models for anticipating global stability, and these models could be applied to identify the susceptibility of pillar failure in the panels of coal mines. T. Sherizadeh [11] used a three-dimensional distinct element method to assess the stability of a room and pillar coal mine in the U.S. Zhang Ji-xiong [17] analyzed the stability of room mining coal pillars during their secondary mining for recovering coal.

In this paper, the Shenfu-Dongsheng mining area (SDMA), where most of the Chinese room mining goafs are located, is taken as an example. First, the characteristics of the room mining goaf are introduced, including the characteristics that were identified during the geological overview and the survey of the goafs. This description is followed by the categorization of the risks induced by room mining goaf and an analysis of the formation mechanisms of each goaf risk. Then, a room mining goaf risk assessment method based on a support vector machine is proposed and verified. Finally, we present our conclusions. This work can greatly contribute to the prediction and prevention of risks induced by room mining goaf.

\section{Characteristics of Room Mining Goaf}

\subsection{Geological Overview}

In China, there is a large number of shallow coal fields, such as the Shenfu, Dongsheng, Lingwu, and Huangling coal fields, at burial depths of less than $150 \mathrm{~m}$. The Shenfu and Dongsheng coal fields are the most typical examples. They are located in the northwest Shaanxi Province and south of the Inner Mongolia Autonomous Region, as shown in Figure 1. Most of the coal seams mined by the room mining method in the SDMA occur at burial depths less than $150 \mathrm{~m}$. The typical occurrence 
characteristics of the coal seam are a shallow burial depth, thin bedrock roof and thick topsoil layer, as shown in Figure 2. It can be seen from the composition of the overlying strata that the bedrock roof of this strata is relatively thin and the topsoil layer is relatively thick. The topsoil layer exerts a large load on the bedrock roof, which decreases the collapse distance of the bedrock and limits the suspended area of the roof. In this case, once some of the pillars in the room mining goaf are damaged, they will lose the capacity to support the roof. The bedrock roof will collapse when the damaged area of the coal pillars reaches a certain threshold. This bedrock roof collapse will lead to the collapse of the topsoil layer, triggering a series of intense disasters.

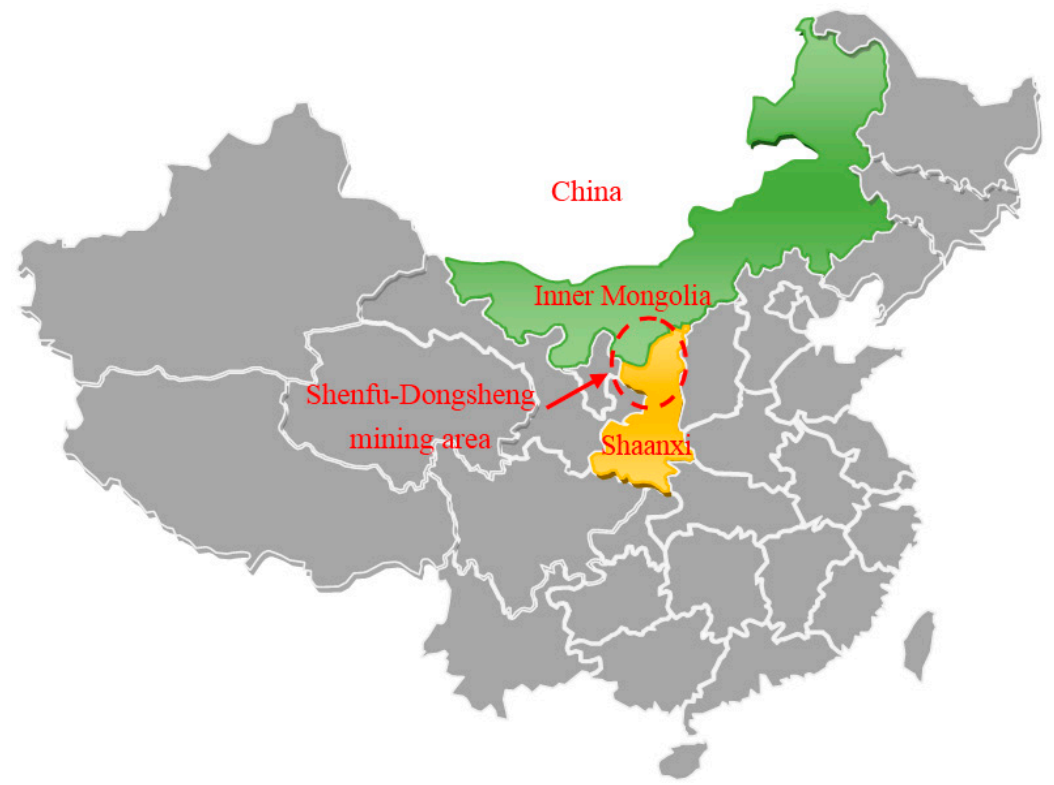

Figure 1. The position of the Shenfu-Dongsheng mining area.

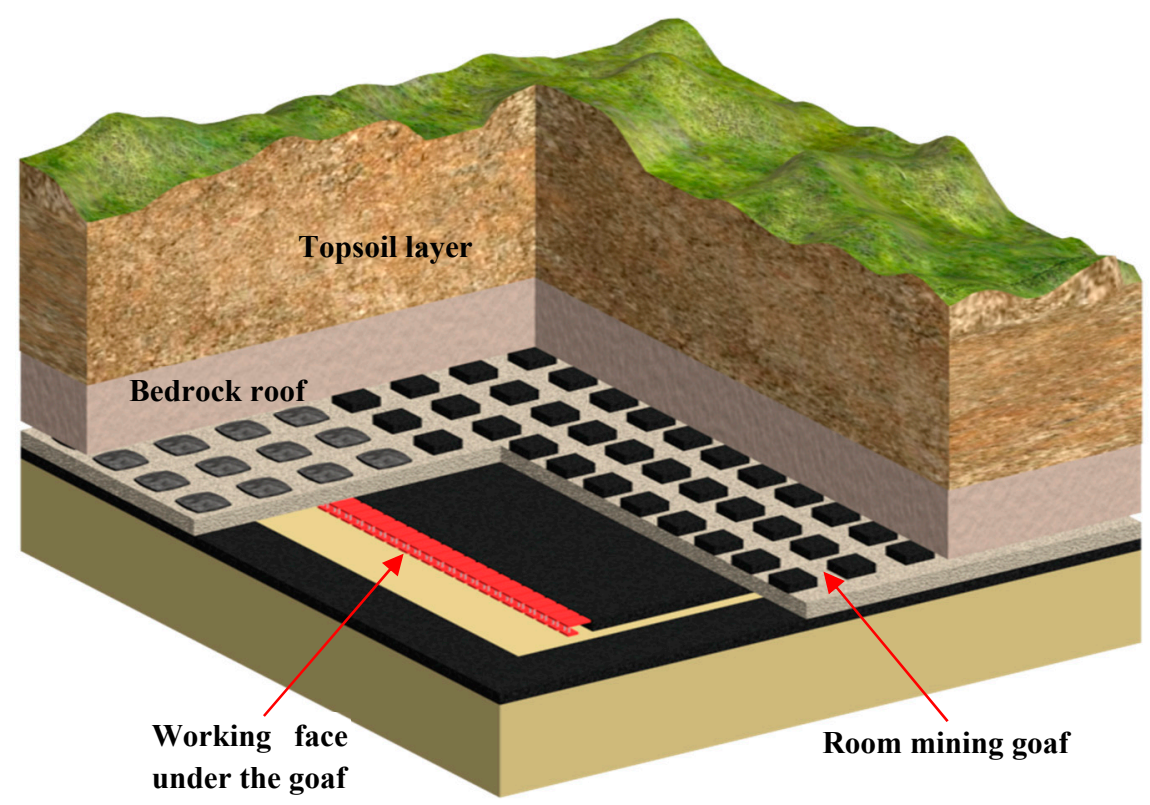

Figure 2. The overburden structure of the room mining goaf in the Shenfu-Dongsheng mining area. 


\subsection{Survey of the Characteristics of the Goaf}

\subsubsection{Introduction to the Survey Methods}

After decades of mining, innumerable goafs have been formed in the SDMA. These goafs are widely distributed and vary in size. In addition, there are no complete, detailed records and data on the scope and state of most of these goafs. However, it is necessary to understand the specific distribution and state of the goafs for prevention of risks and mitigation of their consequences within the goaf areas. Hence, we first conducted a basic data collection and field survey. To obtain a more accurate distribution of the goafs, geophysical exploration, including application of the EH4 magnetotelluric method and high-density resistivity method, and drilling were performed [19]. When interpreting geophysical data, we should make repeated comparisons with the drilling results and geophysical characteristics to perform a comprehensive analysis to determine the distribution of the goafs more precisely and accurately. Due to space limitations, this paper introduces only some of the survey results. Figures $3-5$ show examples of the results obtained through these methods. From these results, we can identify the goaf area, the waterlogged area, the burned area, etc.

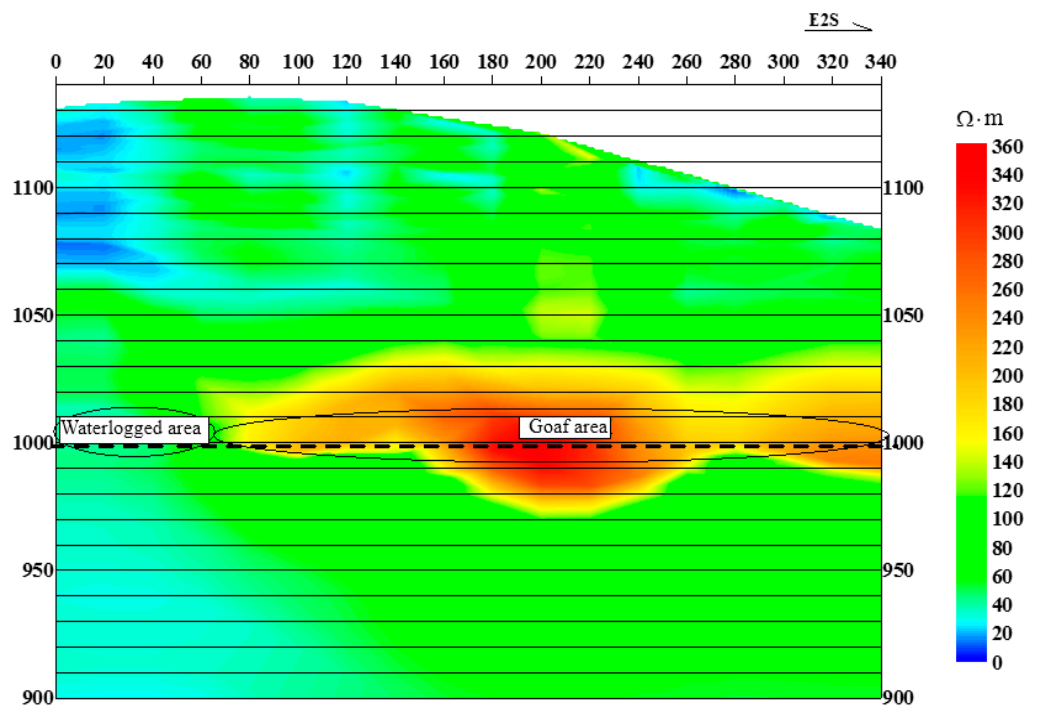

Figure 3. Resistivity section obtained by inversion techniques (an example of the application of the EH4 magnetotelluric method).

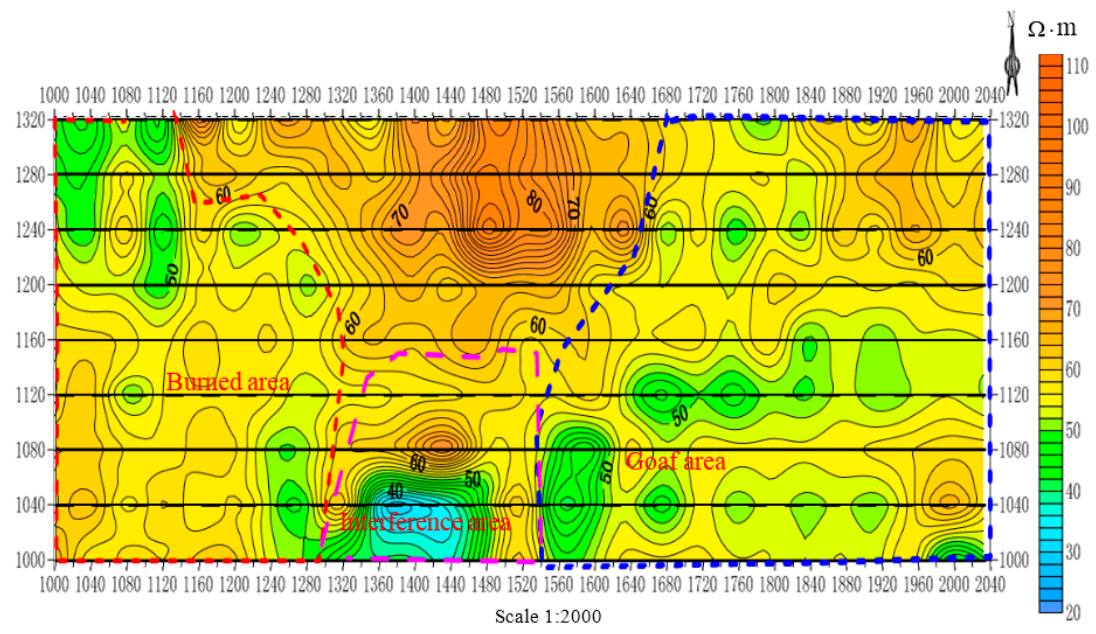

Figure 4. Horizontal slice map of the apparent resistivity of the coal seam (an example of the application of the high-density resistivity method). 


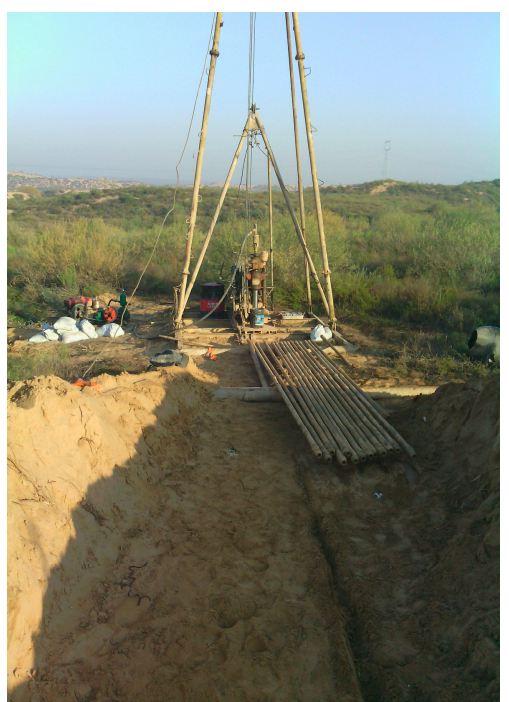

(a)

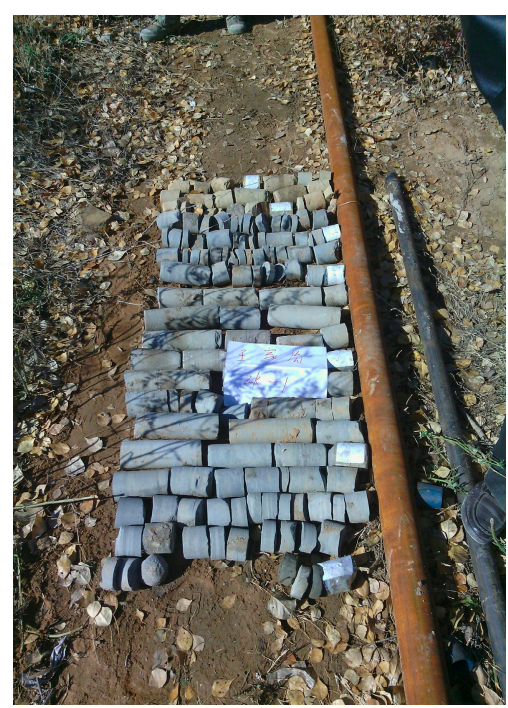

(b)

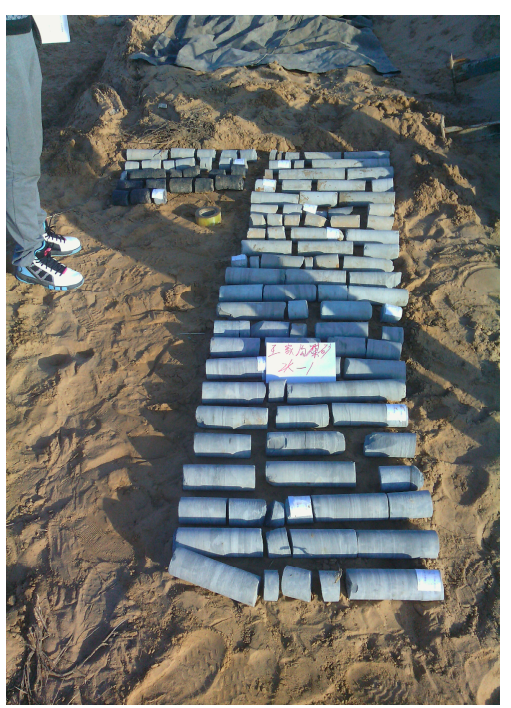

(c)

Figure 5. Examples of the drilling process to determine the goaf distribution: (a) Field photos of drilling construction; (b) Core from exploration drilling; and (c) Core used to validate the geophysical exploration.

\subsubsection{Example of the Survey Results}

The Shendong Coal Group, a large coal company in the Shendong Mining Area, is taken as a case study. Through the investigation and exploration of the coal mines of the Shendong Coal Group, such as the Shangwan Coal Mine, Cuncaota No. 2 Coal Mine, and Daliuta Coal Mine, we found that the area of room mining goaf has reached 29 million 57 thousand $\mathrm{m}^{2}$ (see Table 1 for details). The distribution of the room mining goaf among the coal mines is shown in Figure 6.

Table 1. Areal statistics of the room mining goaf (unit: $10,000 \mathrm{~m}^{2}$ ).

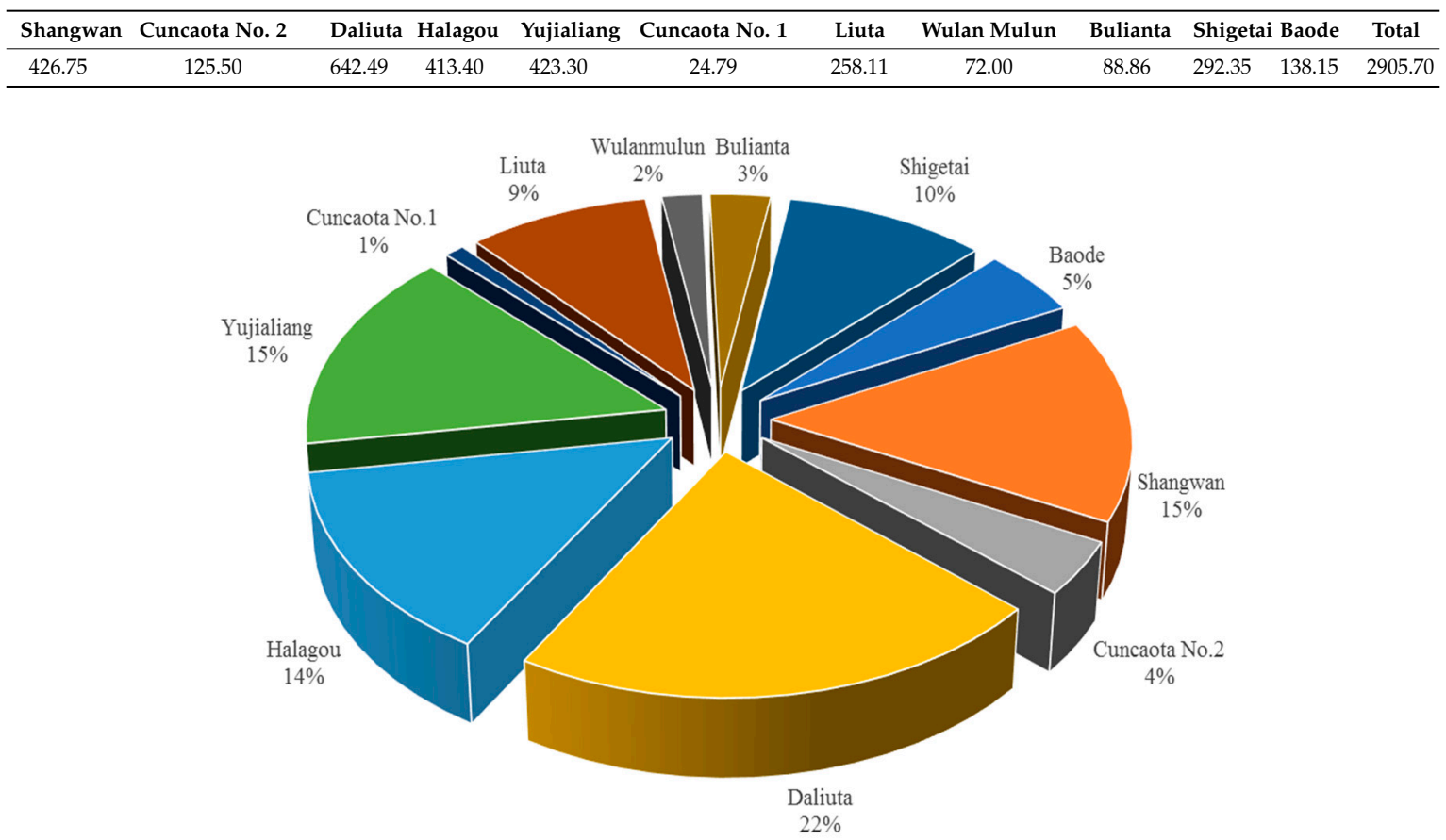

Figure 6. The distribution of the room mining goaf among the mines of the Shendong Coal Group. 
The survey results also show that although the surfaces of some goafs have partially collapsed, there are no clear signs of collapse in most of the goafs. In some goafs, there is water accumulation. In some goafs, the coal has spontaneously combusted. Some of the new mining faces are located near the room mining goafs or under the room mining goafs. In addition, there are also buildings, highways, high-pressure towers, etc. at the ground surface above these room mining goafs. Because the pillars cannot perpetually retain their stability, the sudden collapse of a large area of the roof and surface subsidence will ultimately occur under the influence of the increase in the surface load or the stress due to nearby mining disturbance. This will cause the destruction of the surface structures, occurrence of rock burst near the mining face, emission of harmful gas, occurrence of roof accident, etc. as well as major geological disasters in the mining area.

\section{Risks Induced by Room Mining Goaf}

\subsection{Common Types and Formation Mechanisms}

The categorization of risks induced by room mining goaf is of significance and relevant to the efforts of risk control in Chinese coal mines. On the basis of a complete survey of the room mining goafs, this paper has outlined eight goaf risks, emphasizing the types of goaf risks that require precautions, and presents an analysis on the formation mechanisms of each goaf risk [20].

\subsubsection{Serious Waste of Coal Resources}

In the room mining method, the roof of the goaf is supported by coal pillars. To ensure safety during mining, the sizes of the coal pillars are usually large. The retention of a large number of coal pillars results in a very low recovery rate of the coal resources. The recovery rate of the mining areas is less than $50 \%$, and the recovery rate of the mines is generally between $20 \%$ and $30 \%$. Figure 7 shows the coal pillar exposed in the comprehensive treatment (stripping) of a room mining goaf. It can be seen that the sizes of the coal pillars are very irregular, the shapes are different, and the waste of coal resources is astonishing. Yet, a considerable waste of coal resources has not directly caused a risk. Coal resources are not renewable, and a large waste may pose a serious risk to the sustainable development of humans. Therefore, we include this risk type here.

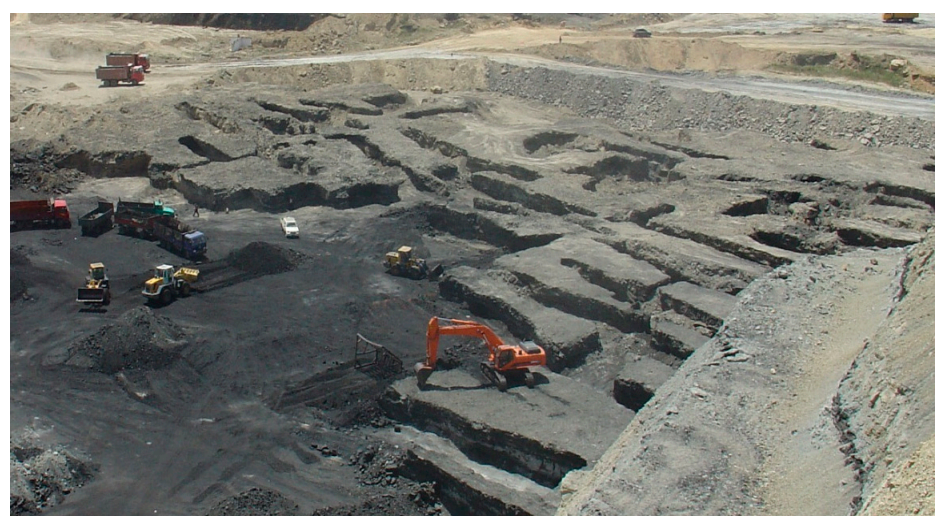

Figure 7. Recovery of the residual coal in room mining goaf by stripping.

\subsubsection{Hidden Danger Caused by Accumulated Toxic and Harmful Gases}

There is a considerable amount of methane, carbon dioxide, nitrogen and a small amount of ethane, ethylene, carbon monoxide, hydrogen sulfide, sulfur dioxide and other toxic and harmful gases in the goafs. On the one hand, the gases may cause severe anoxia and suffocate personnel; on the other hand, they can also cause a regenerative fire. When a fire broke out, the dry distillation of coal seam can be as a result of the temperature increase. Then, some flammable and explosive gases, such as methane, ethylene, acetylene and hydrogen, may be produced. Therefore, there is a danger of gas 
explosion when there is a fire in a gas-free mine, which seriously threatens the safety of underground personnel. For example, there have been harmful carbon monoxide gas incidents, resulting in six casualties in the goaf of the Xinju mine, Ordos City. Figure 8 shows a schematic diagram of the toxic and harmful gases that hurt personnel and cause explosions.

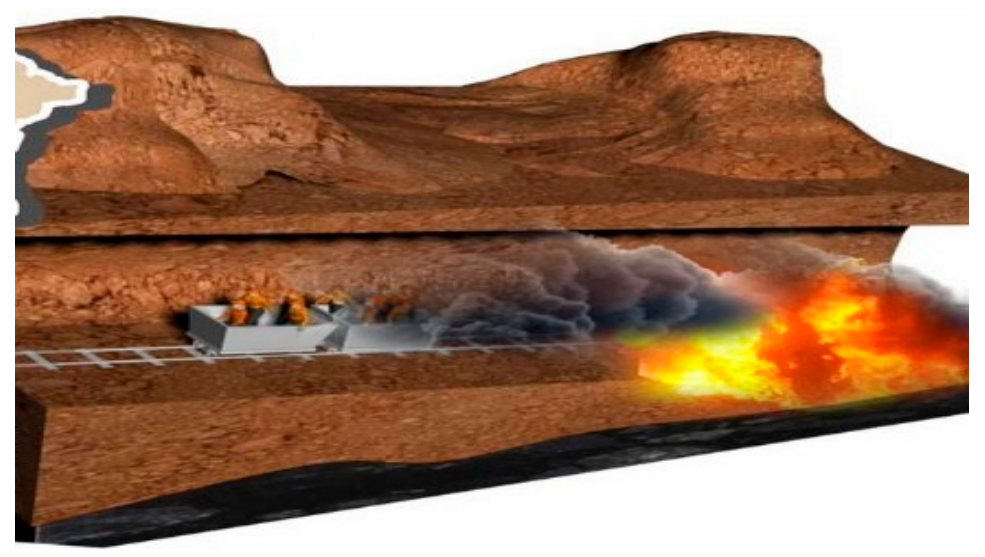

Figure 8. Schematic diagram of toxic and harmful gases hurting personnel and causing explosions.

\subsubsection{Water Inrush Accident Caused by Accumulated Water}

The distribution of a large number of room mining goafs is not clear. During the process of mining, if the excavation space and the goaf are connected, the water in the goaf will suddenly pour into the excavation space, causing major safety accidents. Moreover, if the height of the fracture zone of the lower coal exceeds the spacing of the coal seams, the accumulated water in the goaf will flow into the working face of the lower coal seam, resulting in a water burst accident in the lower mining space, as shown in Figure 9. More seriously, if the excavation engineering activities in the surrounding mines destroy the water body in the goaf, the water will suddenly burst into the mine and cause harm to the mine. In addition, under the long-term corrosion action of the groundwater, the strength of the coal pillars, roof and floor will decrease, and the collapse of a large area of the roof may occur. Then, the goaf closed wall will be washed away, and the accumulated water in the goaf will burst onto the nearby working face.

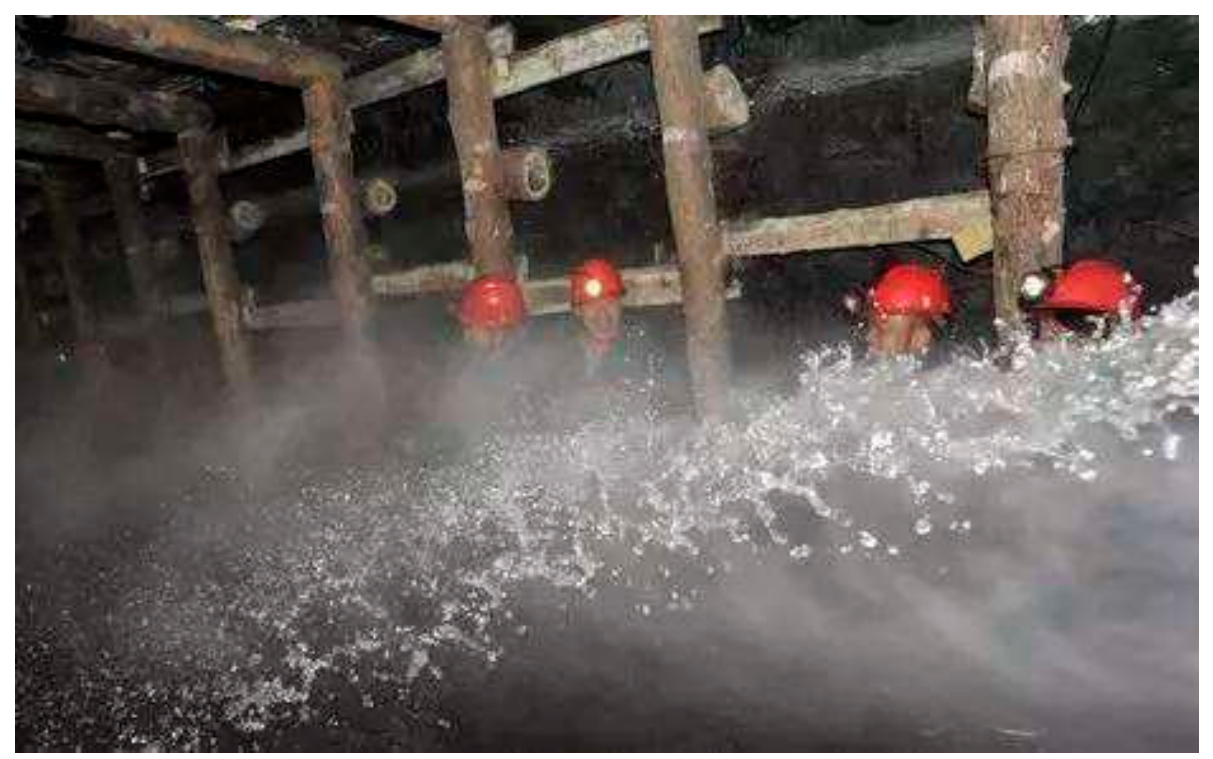

Figure 9. Water inrush accident caused by accumulated water in the goaf. 


\subsubsection{Damage of Surface Construction Caused by Goaf Collapse}

In the goaf formed by the room mining method, the roof will generally not collapse immediately after mining, and the surface deformation is small. Therefore, due to insufficient mining and non-sufficient deformation of the surrounding rock, an unfilled hole will exist for a long time in the old mining area. However, with time and the expansion of the mining area, the coal pillars may gradually become damaged. Hence, it is difficult to ensure the permanent stability of the surface of the goaf. A disaster may occur decades or even a century after mining. There are hidden dangers in the instability and collapse of room mining goaf, which pose a great threat to surface construction, such as highways, railways, high-voltage line towers and houses, as shown in Figure 10.

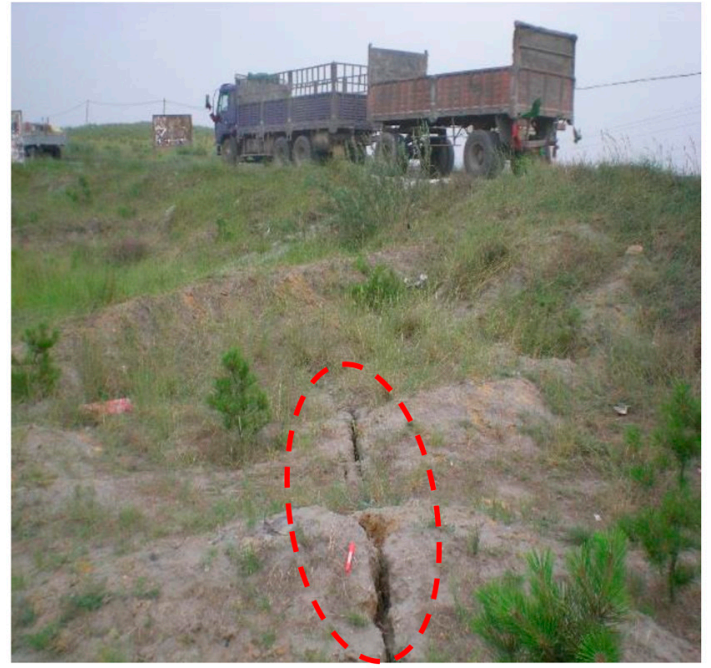

(a)

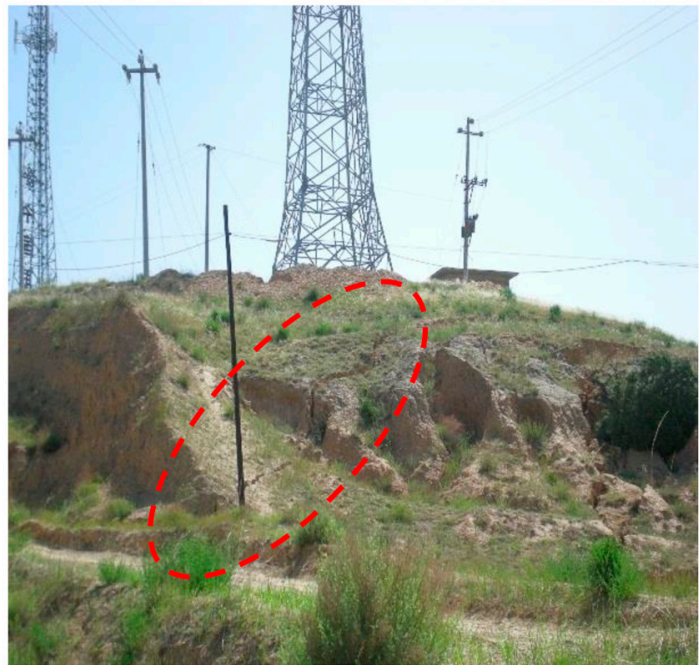

(b)

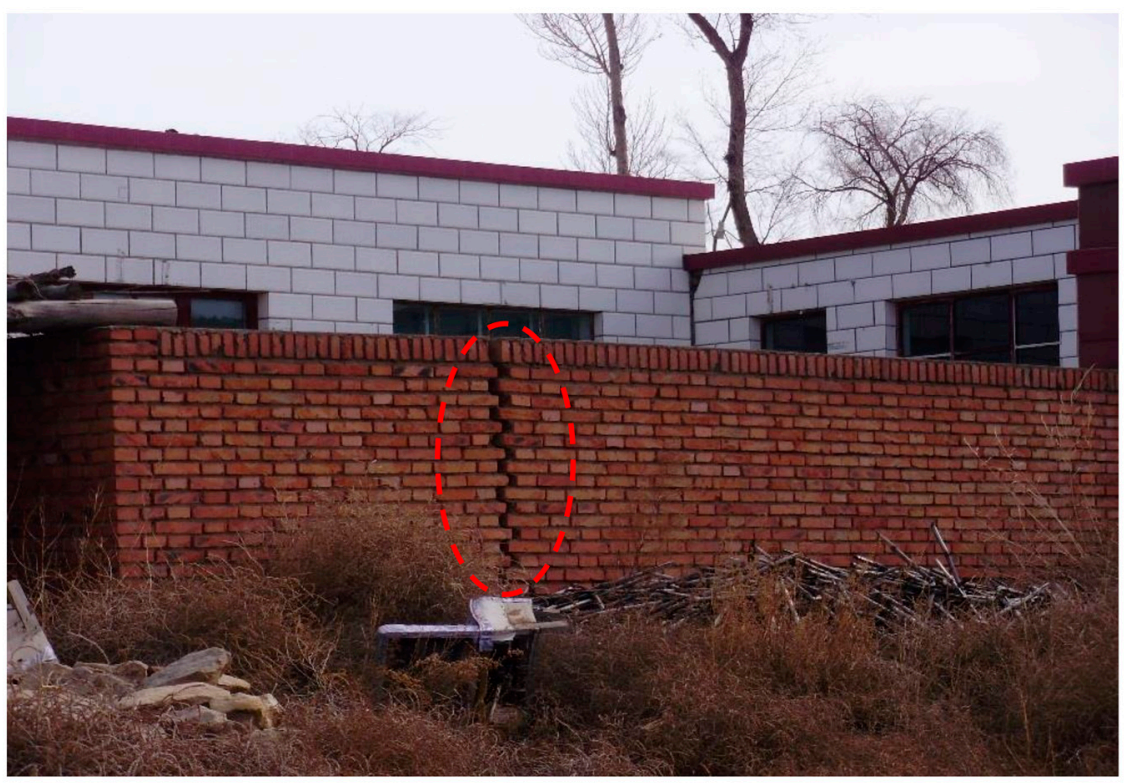

(c)

Figure 10. Damage of surface construction caused by goaf: (a) slope failure of a highway; (b) foundation destruction of a signal tower; and (c) wall crack in a house. 


\subsubsection{Spontaneous Combustion of the Coal Seam in Goaf}

There is a large amount of space in the room mining goaf. The airtightness of this space is poor, and shallow surface cracks can also pass through the goaf, causing the goaf to undergo air leakage for a long time. Due to the large number of coal pillars and floating coal that are left from room mining, the entry of oxygen greatly increases the possibility of spontaneous combustion of the remaining coal pillars and floating coal in the areas that have been mined. The coal seam may cause spontaneous combustion or deteriorate and lose value if recovered, as shown in Figure 11. The situation of spontaneous combustion of the coal seam in the mine will not only seriously affect the safe exploitation of the adjacent coal mines and the lower coal within this mine, but also waste many valuable resources and cause severe pollution of the environment.

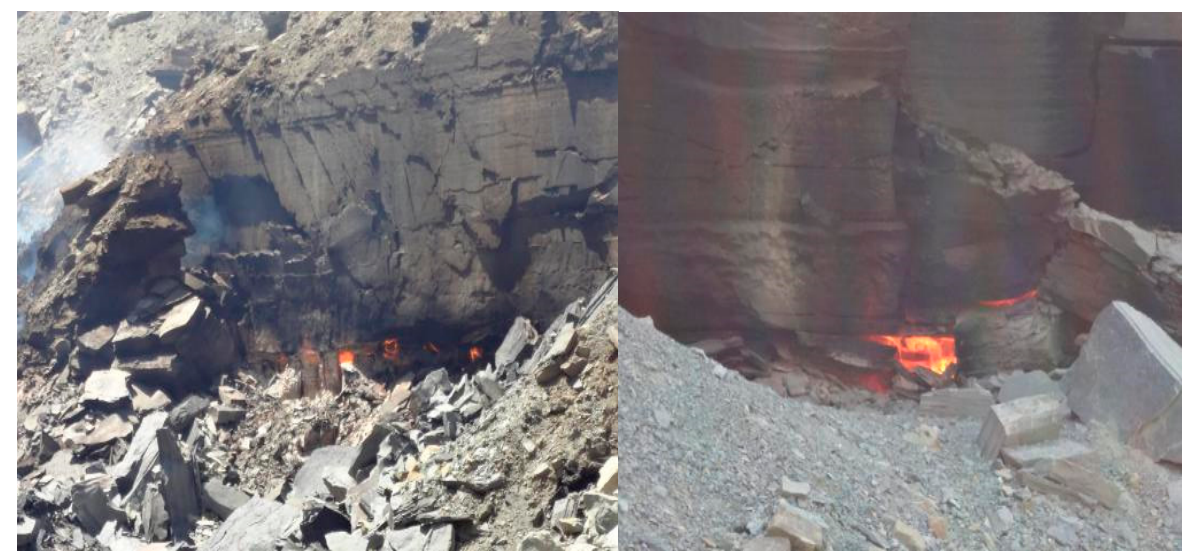

Figure 11. Spontaneous combustion of the coal seam.

\subsubsection{Groundwater Resource Loss Caused by the Collapse of Goaf}

The collapse of the goaf will lead to a change in the hydrogeological conditions in the mining area, thereby changing the groundwater power field. The typical characteristics of the room mining goaf are a shallow burial depth, thinner bedrock roof and thicker topsoil layer. After coal mining, the phreatic aquifer covered by the topsoil layer and groundwater reservoir is damaged, and the groundwater is gradually drained, decreasing the regional groundwater level. This causes considerable danger to the lives of the inhabitants, the ecological environment and the sustainable development of the energy base. Figure 12 shows an abandoned dry well above the room mining goaf.

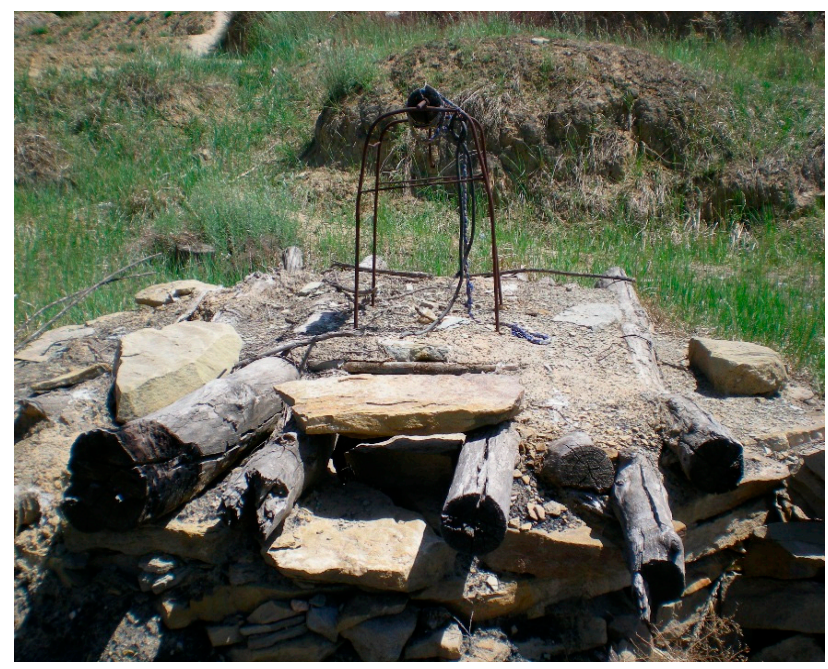

Figure 12. An abandoned dry well above the room mining goaf. 


\subsubsection{Geological Disasters Caused by Goaf Collapse}

A large number of coal pillars have been left in the goafs and may eventually be destroyed, causing roof collapse. The collapse of a large area of goafs will produce impact waves. This may crush the airtight walls of the goafs, causing toxic and harmful gases to enter or bricks to eject as well as casualties and equipment damage in underground areas adjacent to the goafs. In addition, the collapse of a large area of the goafs will also cause great damage to the surface and lead to mine earthquakes due to the subsidence, as shown in Figure 13. For example, the Shaanxi mine earthquake information network shows that in 2012 alone, 13 mine earthquakes occurred in Yulin City, with a largest magnitude of 3.3, mostly caused by the collapse of goafs. The mine earthquakes, due to the subsidence, have become one of the main factors that affects the stability of the local communities.
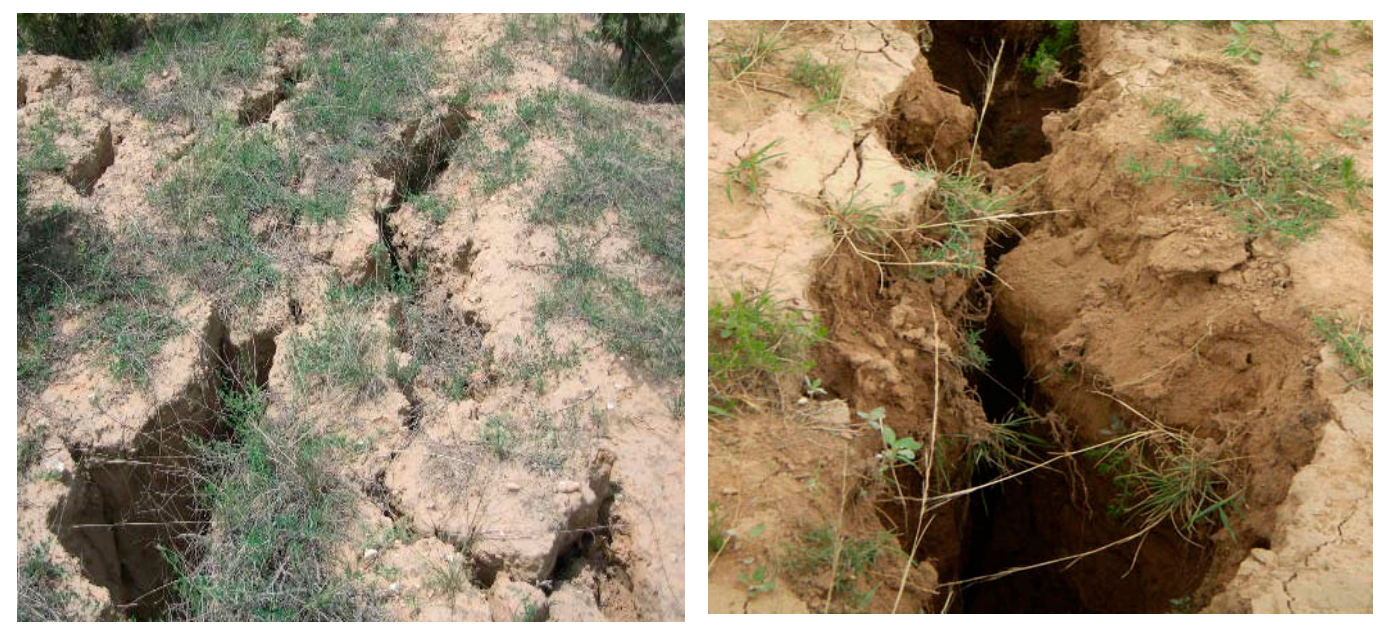

Figure 13. Surface cracks caused by goaf collapse.

\subsubsection{Power Disasters during Mining of the Coal Seam under Goaf}

Coal pillars that were left in the room mining goaf can result in stress concentrations on the floor, and the concentrated stress will transfer downward. When the lower coal is mined, the stress concentration is extremely unfavorable for the roof support of the working face in the lower coal. In severe cases, rock burst will also be induced, as shown in Figure 14. Moreover, multiple mining phases will cause the coal pillars to decrease in strength and even fail, which eventually leads to the collapse of the whole goaf. In addition, the water and harmful gas in the goaf will pour into the lower working face. In short, the mining of the lower coal under room mining goaf is in danger of a power disaster, such as rock burst and water inrush. This is a considerable safety hazard in the production of coal mines.

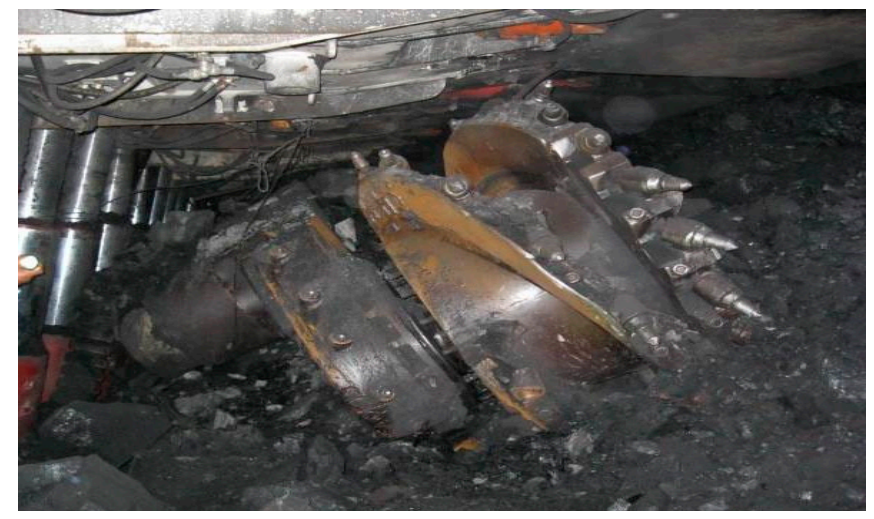

Figure 14. Rock burst of working face in the lower coal caused by stress concentration. 


\subsection{Comprehensive Risk Analysis}

Through a comprehensive analysis of the common types and formation mechanisms of the risks induced by room mining goafs, it can be seen that the risks are dynamic and nonlinear and the risks gradually accumulate and superimpose. The occurrence of a risk may lead to several other risks, there is a certain interaction between the risks. Surface subsidence is the most common type and often occurs when other risks occur. More specific details of the risk types, causes and scope of influence are as shown in Table 2.

Table 2. The risk type, causes and scope of influence in room mining goaf.

\begin{tabular}{|c|c|c|}
\hline Risk Type & Causes & Scope of Influence \\
\hline Waste of Coal Resources & The retention of a large number of coal pillars. & $\begin{array}{l}\text { The sustainability of the ecological } \\
\text { environment. }\end{array}$ \\
\hline Water Inrush & $\begin{array}{l}\text { The new excavation space is directly } \\
\text { connected with the old space or is connected } \\
\text { through the fissures. }\end{array}$ & $\begin{array}{l}\text { Underground operation personnel } \\
\text { as well as equipment and facilities } \\
\text { in some areas or the whole mine. }\end{array}$ \\
\hline Spontaneous Combustion & $\begin{array}{l}\text { The fissures in the goaf communicate with the } \\
\text { surface, and the heat of the oxidation reaction } \\
\text { in the goaf cannot be diffused in time }\end{array}$ & $\begin{array}{l}\text { Underground operation personnel } \\
\text { as well as equipment and facilities } \\
\text { in some areas or the whole mine. }\end{array}$ \\
\hline Impact waves & $\begin{array}{l}\text { The gas in the goaf is compressed because a } \\
\text { large area of the roof of the goaf suddenly } \\
\text { collapses. }\end{array}$ & $\begin{array}{l}\text { Underground operation personnel } \\
\text { as well as equipment and facilities } \\
\text { in some areas or the whole mine. }\end{array}$ \\
\hline Rock burst & $\begin{array}{l}\text { The existence of the goaf intensifies the stress } \\
\text { concentration. }\end{array}$ & $\begin{array}{l}\text { Underground operation personnel } \\
\text { as well as equipment and facilities } \\
\text { in some areas. }\end{array}$ \\
\hline Mine earthquake & $\begin{array}{l}\text { The composite effect of mechanical shock, } \\
\text { impact waves and rock burst caused by the } \\
\text { sudden collapse of a large area of the roof. }\end{array}$ & $\begin{array}{l}\text { Surface and underground } \\
\text { operation personnel as well as } \\
\text { equipment and facilities in the } \\
\text { whole mine. }\end{array}$ \\
\hline Air leakage into goaf & Fresh air flows into the goaf. & $\begin{array}{l}\text { Underground operation personnel } \\
\text { in some areas. }\end{array}$ \\
\hline Emission of toxic and harmful gases & $\begin{array}{l}\text { The toxic and harmful gases diffuse to the } \\
\text { surface or underground mining spaces } \\
\text { through fissures. }\end{array}$ & $\begin{array}{l}\text { Underground operation personnel; } \\
\text { residents or livestock, etc. }\end{array}$ \\
\hline Surface subsidence & $\begin{array}{l}\text { The roof of the goaf (suddenly) collapses, and } \\
\text { the collapse develops to the surface. }\end{array}$ & $\begin{array}{l}\text { Surface construction (residential, } \\
\text { highway, high pressure line tower, } \\
\text { signal tower, etc.). }\end{array}$ \\
\hline Crushing of the airtight wall & $\begin{array}{l}\text { The roof of the goaf suddenly collapses, and } \\
\text { the resistance of the airtight wall is poor. }\end{array}$ & $\begin{array}{l}\text { Underground operation personnel } \\
\text { as well as equipment and facilities } \\
\text { in some areas. }\end{array}$ \\
\hline Water level lowering and water shortages & $\begin{array}{l}\text { The water of the aquifer flows into the goaf } \\
\text { through the connection. }\end{array}$ & $\begin{array}{l}\text { Water use in underground work } \\
\text { and water for surrounding } \\
\text { residents. }\end{array}$ \\
\hline Landslide & $\begin{array}{l}\text { The collapse of the goaf has developed to the } \\
\text { surface. }\end{array}$ & Mountains and slopes. \\
\hline
\end{tabular}

\section{Risk Assessment of Room Mining Goaf}

At present, due to the constraints of the economic and technological conditions, it is not possible to fully implement on-line monitoring of goaf and an early warning system. Therefore, it is of great significance to use the most advanced research results of modern nonlinear mathematics and information science to establish a nonlinear prediction model based on the cognitive degree of the understanding of the disaster mechanisms of room mining goaf. This model can help make decisions on the surveying and management of the hidden dangers of room mining goaf.

\subsection{Selection of Risk Assessment Methods for Room Mining Goaf}

In this paper, the purpose of the risk assessment of room mining goaf is to judge and classify the severity of the danger of the existing goafs. The common classification methods are the Delphi 
method, index evaluation method, artificial neural network method and support vector machine method. Compared with other methods, support vector machines have the advantages of no local extremum, fewer training samples and a simple network structure. It has many unique advantages in solving small-sample, nonlinear and high-dimensional pattern recognition, and can be extended to other machine learning problems, such as function fitting. In recent years, support vector machines have been applied in coal mine safety evaluation, risk assessment and other fields [21]. Previous studies show that the support vector machine method is superior to the traditional statistical pattern recognition and fuzzy recognition methods in these fields. The data of room mining goafs in the SDMA are not adequate, and there are few mature training samples for data for risks such as mine earthquakes and collapse. Therefore, it is advantageous to use a support vector machine, which has a prominent advantage in small-sample problems, to assess the goafs in the SDMA. In this paper, a support vector machine is used as the main model to assess the risks of room mining goaf.

\subsection{Support Vector Machine Assessment Model of Room Mining Goaf}

\subsubsection{Determination of Influence Factors and Classification Standard}

To assess the risks of room mining goaf, the impact factors first need to be determined. Considering the impact of various mining and geological factors on the stability of the goaf, ten main factors were identified as the impact factors, and some of these factors were normalized, as shown in Table 3. To conduct a risk assessment of the room mining goaf using a support vector machine, the risk grade and the classification basis need to be determined first. Considering that there is no mature system for classification of the risk grade of room mining goaf, this paper takes the actual condition of the training samples as the classification basis. As described in Section 3.2, The occurrence of a risk may lead to several other risks, there is a certain interaction between the risks. Surface subsidence is the most common type and often occurs when other risks occur. Therefore, the classification standard is related to the surface subsidence. The danger of the goaf is divided into three grades: high risk, medium risk and low risk. Taking 2010 as a time node, the coal mines that have undergone mine earthquakes in recent years are selected as the high-risk training samples, and the corresponding grade is I. Coal mines in which the subsidence area accounts for more than $10 \%$ of the area of the goaf are selected as the medium risk-training samples, and the corresponding grade is II. Coal mines with a nearly undeformed surface above the goaf are selected as the low-risk training samples, and the corresponding grade is III.

Table 3. Impact factors of risk assessment for room mining goaf.

\begin{tabular}{ccccl}
\hline Factor Number & Impact Factor & Factor Sets & Unit & Details of the Influencing Factors \\
\hline F1 & Mining height & {$[1,7]$} & $\mathrm{m}$ & Actual mining height. \\
\hline F2 & Overburden structure & {$[0,1]$} & Dimensionless & The characteristics of the coal seam. \\
\hline F3 & Water accumulation & {$[0,50,000]$} & $\mathrm{m}^{3}$ & Volume of water accumulated in the goaf. \\
\hline F4 & Spontaneous combustion & {$[0,1]$} & Dimensionless & $\begin{array}{l}\text { The state of spontaneous combustion of the } \\
\text { coal pillars in the goaf. }\end{array}$ \\
\hline F6 & Mining disturbance & {$[0,1]$} & Dimensionless & $\begin{array}{l}\text { Mining disturbance to the goaf caused by } \\
\text { work on the nearby coal seam. }\end{array}$ \\
\hline F7 & Width & {$[0.5,2]$} & Dimensionless & $\begin{array}{l}\text { The ratio of the width of the room to the } \\
\text { width of the coal pillar. }\end{array}$ \\
\hline F8 & Coal pillar state & {$[0,6]$} & $\mathrm{m}$ & $\begin{array}{l}\text { The width of the elastic core area of the coal } \\
\text { pillar. }\end{array}$ \\
\hline F9 & Goaf area & {$[0,2.5]$} & $\mathrm{km}{ }^{2}$ & Area of room mining goaf joined together. \\
\hline F10 & Roof and floor & {$[0,1]$} & MPa & $\begin{array}{l}\text { The influence of the strengths of the roof and } \\
\text { floor on the stability of the coal pillar. }\end{array}$ \\
\hline
\end{tabular}




\subsubsection{Construction of the Support Vector Machine Assessment Model}

Support vector machines are determined by training samples and kernel functions. The input samples are determined after the kernel function is determined. In this paper, the radial basis function (RBF) is selected as the kernel function of the support vector machine. The advantages of the RBF are as follows. The RBF has a high universality; the function output of the network state of the RBF is a nonlinear mapping from the input layer to the hidden layer, while the output layer is linear. It effectively solves the linear separable problem after the feature space of the original nonlinear separable problem is transformed to a high-dimensional space; the RBF has a strong divisibility and interpolation ability, can effectively reduce dimension errors and improve the generalization ability of the support vector machine. There are fewer parameters in the RBF, and the calculation work can be greatly reduced. After the kernel function is determined, according to the three proposed damage grades of the room mining goaf, a multiclass support vector machine algorithm of a binary tree recognition strategy (as shown in Figure 15) is used to construct the assessment model. Two support vector machines, $\mathrm{SVM}_{1}$ and $\mathrm{SVM}_{2}$, are constructed. During training, $\mathrm{SVM}_{1}$ takes grade I of the training samples as the positive set and takes grade II and grade III of the training samples as the negative set. $\mathrm{SVM}_{2}$ takes grade II of the training samples as the positive set and takes grade III of the training samples as the negative set to train. Finally, the results of the training are used as the basis for the assessment.

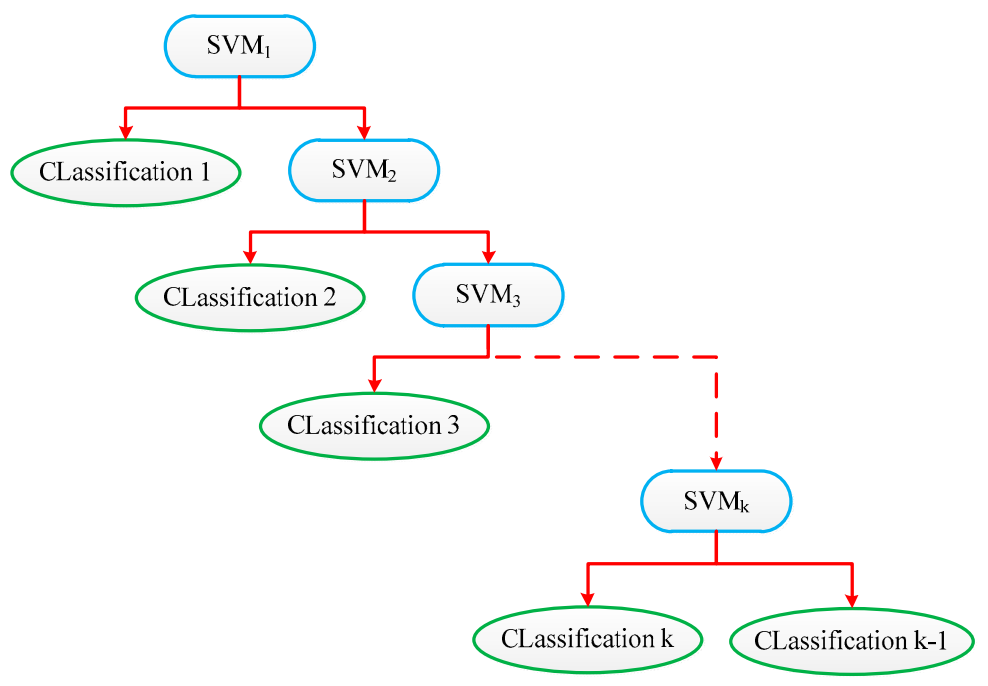

Figure 15. Model diagram of a multiclass support vector machine algorithm of a binary tree recognition strategy.

\subsubsection{Risk Assessment Process and Sample Training}

According to the classification, the appropriate training samples are selected by using the data of the room mining goaf in the SDMA and some coal mines of Yulin as the classification sample set. Table 4 shows the level and classification basis of the training samples. Note that the area of collapse and mine earthquakes often accounts for only part of the mine area. Hence, in the training and testing samples, only one or several adjacent typical panels in each mine are selected. This method has a higher practical value than the method of using the whole mine as a sample. 
Table 4. Grade and classification basis of the training samples.

\begin{tabular}{ccc}
\hline Coal Mine Name & Grade & Classification Standard \\
\hline Shibadun & I & Two mine earthquakes occurred in 2012 \\
Changxing & I & A 2.8 magnitude mine earthquake occurred in 2011 \\
Jinniu & I & A 2.1 magnitude mine earthquake occurred in 2012 \\
Shaqu & I & A 3.0 magnitude mine earthquake occurred in 2011 \\
Bandingliang & II & The ratio of the subsidence area to the goaf area is $10 \%$ \\
Dashata & II & The ratio of the subsidence area to the goaf area is $14 \%$ \\
Sujiata & II & The ratio of the subsidence area to the goaf area is $28 \%$ \\
Xiaosuangou & II & The ratio of the subsidence area to the goaf area is $16 \%$ \\
Yubojie & III & No surface subsidence and no mine earthquake \\
Yujialiang & III & No surface subsidence and no mine earthquake \\
Zhugaita & III & No surface subsidence and no mine earthquake \\
Qianliang & III & No surface subsidence and no mine earthquake \\
\hline
\end{tabular}

The dimensions of the data for each factor are different, and the difference between the values of each factor is large. Therefore, the value of the evaluation factor is normalized. The value of the evaluation factor that cannot be quantified is given in the form of $\{0.1,0.5,0.9\}$ according to the number of the content of the factor value. The value of the quantifiable evaluation factor is mapped to the interval [0 and 1]. The relationship between the original data can be retained in the normalization, avoiding the problem of factors with large values dominating the evaluation results while some important factors with small values are obscured. Normalization also reduces the difficulty of data calculation. An example of the data conversion for normalization for the training samples is shown in Table 5.

Table 5. Conversion table of factors for room mining goaf.

\begin{tabular}{cccccccccc}
\hline F1 & F2 & F3 & F4 & F5 & F6 & F7 & F8 & F9 & F10 \\
\hline 4.2 & 0.1 & 0 & 0.1 & 0.1 & 0.625 & 4 & 1.21 & 0.9 & 2005 \\
0.53 & 0.10 & 0.00 & 0.10 & 0.10 & 0.08 & 0.67 & 0.48 & 0.90 & 0.56 \\
\hline
\end{tabular}

The converted sample data are shown in Table 6, where the target state represents the assessment grade of a training sample.

Table 6. Training assessment set of the room mining goaf.

\begin{tabular}{cccccccccccc}
\hline Coal Mine Name & F1 & F2 & F3 & F4 & F5 & F6 & F7 & F8 & F9 & F10 & Target Status \\
\hline Shibadun & 0.92 & 0.90 & 0.80 & 0.5 & 0.50 & 0.33 & 0.33 & 0.568 & 0.5 & 0.69 & I \\
Changxing & 0.42 & 0.90 & 0.40 & 0.1 & 0.50 & 0.43 & 0.50 & 0.884 & 0.5 & 0.81 & I \\
Jinniu & 0.42 & 0.90 & 0.60 & 0.5 & 0.50 & 0.25 & 0.50 & 0.544 & 0.5 & 0.88 & I \\
Shaqu & 0.37 & 0.50 & 0.00 & 0.5 & 0.50 & 0.50 & 0.33 & 0.168 & 0.5 & 0.88 & I \\
Bandingliang & 0.77 & 0.90 & 0.10 & 0.1 & 0.10 & 1.00 & 0.50 & 0.316 & 0.5 & 0.63 & II \\
Dashata & 0.81 & 0.10 & 0.00 & 0.1 & 0.50 & 0.56 & 0.50 & 0.636 & 0.9 & 0.56 & II \\
Sujiata & 0.41 & 0.10 & 0.00 & 0.1 & 0.50 & 0.56 & 0.50 & 0.196 & 0.5 & 0.69 & II \\
Xiaosuangou & 0.62 & 0.50 & 0.00 & 0.1 & 0.50 & 0.33 & 0.50 & 0.132 & 0.5 & 0.56 & II \\
Yubojie & 0.18 & 0.10 & 0.00 & 0.1 & 0.50 & 0.33 & 0.33 & 0.068 & 0.9 & 0.63 & II \\
Yujialiang & 0.60 & 0.10 & 0.00 & 0.1 & 0.90 & 0.33 & 0.67 & 0.964 & 0.9 & 0.50 & III \\
Zhugaita & 0.23 & 0.10 & 0.00 & 0.1 & 0.50 & 0.20 & 0.50 & 0.128 & 0.9 & 0.88 & III \\
Qianliang & 0.25 & 0.50 & 0.00 & 0.1 & 0.90 & 0.24 & 0.50 & 0.804 & 0.5 & 0.44 & III \\
Shibadun & 0.32 & 0.10 & 0.00 & 0.1 & 0.50 & 0.11 & 0.50 & 0.364 & 0.9 & 0.50 & III \\
\hline
\end{tabular}

\subsection{Test of the Risk Assessment Model}

After the training of the support vector machine is completed, six groups of data that were not trained and are complete are used to test the accuracy of the risk assessment model. The results are shown in Table 7. The target status bar shows the risk assessment result of the normalized data from 
the support vector machine. There is a large subsidence area in the Sujia Coal Mine, and the risk assessment result was grade I, and it is not clear whether a mine earthquake has occurred. There is a large area of collapse in the Tengwei Coal Mine and the 301-room mining goaf of the Cunyi Coal Mine, and the risk assessment results were grade II. There is no obvious collapse in the remaining four mines, and the risk assessment results were grade III. Comparing the risk assessment results and the field investigation, it can be seen that the evaluation model has a high accuracy. However, we will further improve the assessment model in the future, and more detailed classifications will be established. The assessment results can help make decisions on the surveying and management of the hidden dangers of room mining goaf. In the goafs with higher risk grades, precautions should be taken against risk, and priority should be given to goaf management. At present, the comprehensive management of the hidden dangers of goaf mainly includes surface grouting control technology, residual coal pillar recovery technology, strip stripping technology, and roof caving treatment technology.

Table 7. Testing set of room mining goaf.

\begin{tabular}{cccccccccccc}
\hline Coal Mine Name & F1 & F2 & F3 & F4 & F5 & F6 & F7 & F8 & F9 & F10 & Target Status \\
\hline Dabeimao & 0.47 & 0.90 & 0.00 & 0.50 & 0.50 & 0.08 & 0.83 & 1.00 & 0.90 & 0.44 & III \\
Tengwei & 0.20 & 0.50 & 0.00 & 0.50 & 0.90 & 0.33 & 0.33 & 0.50 & 0.10 & 0.50 & II \\
Sujiahao & 0.77 & 0.10 & 0.00 & 0.50 & 0.50 & 0.33 & 0.50 & 0.67 & 0.50 & 0.63 & I \\
Cunyi 3114 area & 0.42 & 0.90 & 0.00 & 0.10 & 0.10 & 0.08 & 1.00 & 1.00 & 0.90 & 0.56 & III \\
Cunyi 301 area & 0.27 & 0.50 & 0.04 & 0.50 & 0.50 & 0.33 & 0.50 & 0.50 & 0.50 & 0.63 & II \\
Hexi & 0.32 & 0.10 & 0.00 & 0.10 & 0.90 & 0.17 & 0.67 & 1.00 & 0.90 & 0.81 & III \\
Zhaojialiang & 0.53 & 0.50 & 0.00 & 0.10 & 0.10 & 0.08 & 0.67 & 1.00 & 0.90 & 0.56 & III \\
\hline
\end{tabular}

\section{Conclusions}

In this paper, the Shenfu-Dongsheng mining area, where most of the Chinese room mining goafs are located, is taken as an example. First, the characteristics of the room mining goaf in the SDMA are introduced, including the characteristics that were identified during the geological overview and the survey of the goafs. This is followed by the categorization of the risks induced by room mining goaf and an analysis of the formation mechanisms of each goaf risk. Then, a risk assessment method of room mining goaf based on a support vector machine is proposed and verified. This work can greatly contribute to the prediction and prevention of risks induced by room mining goaf. The following major conclusions have been drawn:

(1) Most of the coal seam of the Shenfu-Dongsheng mining area mined by the room mining method is buried within $150 \mathrm{~m}$ from the ground surface. The bedrock roof will collapse when the damaged area of the coal pillars reaches a certain extent. This will lead to the collapse of the topsoil layer and a series of serious risks.

(2) Through the survey of the coal mines of the Shendong Coal Group, we found that the room mining goaf area has reached 29 million 57 thousand $\mathrm{m}^{2}$. The survey results show that there are no apparent signs of collapse in most of the goafs. Because the pillars cannot perpetually retain their stability, a sudden roof collapse and a large area of surface subsidence will occur under the influence of the increase in the surface load or the mining-disturbance-induced stress in the vicinity. These processes will cause major geological risks in the mining area.

(3) The categorization of the risks induced by room mining goaf is of significance and relevant to the efforts of risk control in Chinese coal mines. Through a comprehensive analysis of the common types and formation mechanisms of disasters induced by room mining goaf, it can be seen that it can be seen that the risks are dynamic and nonlinear and the risks gradually accumulate and superimpose. The occurrence of a risk may lead to several other risks, there is a certain interaction between the risks. Surface subsidence is the most common type and often occurs when other risks occur. 
(4) It is advantageous to use a support vector machine, which has a prominent advantage in small-sample problems, to assess the goafs in the SDMA. The mining height, overburden structure, water accumulation characteristics, spontaneous combustion occurrence, mining disturbance, width, coal pillar state, goaf area, strength of the mining room roof and floor, and time are the main controlling factor of goaf risk. Comparing the risk assessment results with the field investigation results, it can be seen that the evaluation model has a high accuracy.

Acknowledgments: This work is supported by the National Natural Science Foundation of China (No. 51379117 and No.51479108), the Scientific Research Foundation of Shandong University of Science and Technology for Recruited Talents (2015RCJJ048), Taishan Scholar Talent Team Support Plan for Advantaged and Unique Discipline Areas and the Provincial Natural Science Foundation of Shandong Province, China (ZR2017PEE018).

Author Contributions: All the authors contributed to publishing this paper. Hengjie Luan and Yujing Jiang contributed to the formulation of the overarching research goals and aims; Huili Lin and Pu Wang contributed to the collection and survey of basic date; Yahua Wang and Jiankang Liu provided language and pictures supports.

Conflicts of Interest: The authors declare no conflict of interest.

\section{References}

1. Zipf, R.K. Toward Pillar Design to Prevent Collapse of Room-and-Pillar Mines. 2011. Available online: https:/ / www.cdc.gov/niosh/mining/UserFiles/works/pdfs/tpdtp.pdf (accessed on 21 March 2017).

2. Yu, Y.; Chen, S.; Deng, K.; Fan, H. Long-term stability evaluation and pillar design criterion for room-and-pillar mines. Energies 2017, 10, 1644. [CrossRef]

3. Mathey, M.; van der Merwe, J.N. Critique of the South African squat coal pillar strength formula. J. S. Afr. Inst. Min. Metall. 2016, 116. [CrossRef]

4. Mohan, G.M.; Sheorey, P.R.; Kushwaha, A. Numerical estimation of pillar strength in coal mines. Int. J. Rock Mech. Min. Sci. 2001, 38, 1185-1192. [CrossRef]

5. Torres, V.F.N.; Da Gama, C.D.; E Silva, M.C.; Neves, P.F.; Xie, Q. Comparative stability analyses of traditional and selective room-and-pillar mining techniques for sub-horizontal tungsten veins. Int. J. Min. Metall. Mater. 2011, 18, 1-8. [CrossRef]

6. Esterhuizen, G.S.; Dolinar, D.R.; Ellenberger, J.L. Pillar strength in underground stone mines in the United States. Int. J. Rock Mech. Min. Sci. 2011, 48, 42-50. [CrossRef]

7. Kostecki, T.; Spearing, A.J.S. Influence of backfill on coal pillar strength and floor bearing capacity in weak floor conditions in the Illinois Basin. Int. J. Rock Mech. Min. Sci. 2015, 76, 55-67. [CrossRef]

8. Salmi, E.F.; Nazem, M.; Karakus, M. The effect of rock mass gradual deterioration on the mechanism of post-mining subsidence over shallow abandoned coal mines. Int. J. Rock Mech. Min. Sci. 2017, 91, 59-71. [CrossRef]

9. Poulsen, B.A.; Shen, B. Subsidence risk assessment of decommissioned bord-and-pillar collieries. Int. J. Rock Mech. Min. Sci. 2013, 60, 312-320. [CrossRef]

10. Dehghan, S.; Shahriar, K.; Maarefvand, P.; Goshtasbi, K. 3-D numerical modelling of Domino failure of hard rock pillars in Fetr6 Chromite Mine, Iran, and comparison with empirical methods. J. Cent. South Univ. 2013, 20, 541-549. [CrossRef]

11. Sherizadeh, T.; Kulatilake, P.H.S.W. Assessment of roof stability in a room and pillar coal mine in the U.S. using three-dimensional distinct element method. Tunn. Undergr. Sp. Technol. 2016, 59, 24-37. [CrossRef]

12. Castellanza, R.; Gerolymatou, E.; Nova, R. An attempt to predict the failure time of abandoned mine pillars. Rock Mech. Rock Eng. 2008, 41, 377-401. [CrossRef]

13. Sahu, P.; Lokhande, R.D. An investigation of sinkhole subsidence and its preventive measures in underground coal mining. Procedia Earth Planet. Sci. 2015, 11, 63-75. [CrossRef]

14. Li, C.; Xu, J.; Wang, Z.; Qin, S. Domino instability effect of surrounding rock-coal pillars in a room-and-pillar gob. Int. J. Min. Sci. Technol. 2013, 23, 913-918. [CrossRef]

15. Ghasemi, E.; Shahriar, K.; Sharifzadeh, M.; Hashemolhosseini, H. Quantifying the uncertainty of pillar safety factor by Monte Carlo simulation-A case study. Arch. Min. Sci. 2010, 55, 623-635. 
16. Clarke, B.G.; Welford, M.; Hughes, D.B. The Threat of Abandoned Mines on the Stability of Urban Areas. 2006. Available online: http:/ /iaeg2006.geolsoc.org.uk/cd/papers/iaeg_379.pdf (accessed on 18 November 2016).

17. Zhang, J.; Huang, P.; Zhang, Q.; Li, M.; Chen, Z. Stability and control of room mining coal pillars-Taking room mining coal pillars of solid backfill recovery as an example. J. Cent. South Univ. 2017, 24, 1121-1132. [CrossRef]

18. Ghasemi, E.; Ataei, M.; Shahriar, K. Prediction of global stability in room and pillar coal mines. Nat. Hazards 2014, 72, 405-422. [CrossRef]

19. Sun, H.; Cheng, M.; Su, C.; Li, H.; Zhao, G.; Su, M.; Li, S.; Zhang, B.; Zhang, L.; Li, K. Characterization of shallow karst using electrical resistivity imaging in a limestone mining area. Environ. Earth Sci. 2017, 76, 767. [CrossRef]

20. Gui, H.; Lin, M. Types of water hazards in China coalmines and regional characteristics. Nat. Hazards 2016, 84, 1501-1512. [CrossRef]

21. Yang, L.; Lu, H.; Zhang, X.; Sheng, W. Application research of multiclass support vector machines in coal mine safety evaluation. J. Saf. Sci. Technol. 2012, 4, 111-115. (In Chinese)

(C) 2018 by the authors. Licensee MDPI, Basel, Switzerland. This article is an open access article distributed under the terms and conditions of the Creative Commons Attribution (CC BY) license (http:/ / creativecommons.org/licenses/by/4.0/). 